\title{
In vitro investigation of individual and combined cytotoxic effects of ochratoxin A and other selected mycotoxins on renal cells
}

\author{
A.H. Heussner, D.R. Dietrich, E. O’Brien * \\ Department of Environmental Toxicology, University of Konstanz, Jakob-Burkhardt-St. 25, P.O. Box X-918, 78457 Konstanz, Germany
}

\begin{abstract}
Hundreds of mycotoxins are known to date and many of them are of great interest with regard to human and animal health since they are detected frequently in plant-derived products. Various mycotoxins may occur simultaneously, depending on the environmental and substrate conditions. Considering this coincident production, it is very likely, that humans and animals are always exposed to mixtures rather than to individual compounds. Therefore, future risk assessments should consider mixture toxicity data. This is particularly true for ochratoxin A (OTA), ochratoxin B (OTB), citrinin (CIT) and occasionally for patulin (PAT) as they are all produced by a number of Penicillium and Aspergillus species. Therefore, these four toxins were chosen to study the interactive effects in vitro, using the well-established porcine renal cell line LLC-PK1 and the MTT reduction test as a cytotoxicity endpoint. By application of a step-wise approach to test combination toxicity, using various full factorial as well as a central composite experimental designs, the interactive (synergistic) cytotoxic effects of the these four toxins were assessed. The results obtained in this study confirm a potential for interactive (synergistic) effects of CIT and OTA and possibly other mycotoxins in cells of renal origin.
\end{abstract}

Keywords: Mycotoxins; Renal cells; Combination toxicity

\section{Introduction}

Mycotoxins are secondary metabolites of various molds. To date more than 300 mycotoxins are known and their effects have at least partially been characterized (Engelhardt, 2004; O'Brien and Dietrich, 2005a). These toxins are of great interest with regard to human and animal health since according to the estimations of the UN Food and Agriculture Organization (FAO) approximately $25 \%$ of world food production is contaminated with at least one mycotoxin. Some of these toxins have already been identified to be the causal agents in the development of renal diseases in pigs (e.g., myco-

\footnotetext{
${ }^{*}$ Corresponding author. Tel.: +49 7531 884664; fax: +497531 883170 .

E-mail address: evelyn.Obrien@uni-konstanz.de (E. O’Brien).
}

toxin-induced porcine nephropathy, MPN) (Stoev et al., 1998). As the renal anatomy and morphology of the porcine kidney is very similar to that of human kidneys it is expected that humans would also be susceptible to mycotoxins known to have renal effects in pigs. Indeed, Human Balkan Endemic Nephropathy (BEN), which shows similar renal pathology to MPN, has also been associated with mycotoxin exposure (Fillastre, 1997; Peraica et al., 1999; Pfohl-Leszkowicz et al., 2002; Stoev, 1998; Tatu et al., 1998; Wafa et al., 1998).

In recent years, research efforts have concentrated on the investigation of the effects of individual mycotoxins on the kidney, both in vivo and in vitro (O'Brien and Dietrich, 2005b). One of the toxin families which has been studied intensively is the ochratoxin family. Ochratoxins are produced by various Penicillium and Aspergillus species, several isoforms occur naturally and are often co-produced. The major compound and the most 
toxic form is ochratoxin A (OTA), followed by ochratoxin B (OTB), which differs from OTA only by the substitution of chlorine by hydrogen in the isocoumarin moiety. OTA has been linked to several human and animal diseases including BEN, urothelial tumors and MPN (Fillastre, 1997; Peraica et al., 1999; PfohlLeszkowicz et al., 2002; Stoev, 1998; Stoev et al., 1998, 2002; Tatu et al., 1998; Wafa et al., 1998).

Many mycotoxins may be produced by one mold, in particular, many Aspergillus and Penicillium species can produce several mycotoxins simultaneously, depending on the environmental and substrate conditions. This is particularly true for OTA, OTB, citrinin (CIT) and occasionally for patulin (PAT), the latter two of which have also been associated with alterations in renal function and/or the development of renal pathologies (Martins et al., 2002; Speijers and Speijers, 2004). This fact leads to the question of whether these mycotoxins interact which each other. To date, very little is known about potential interactive toxic effects and presently available data is largely controversial. Those studies, which have been carried out do indeed indicate a potential for interactive or synergistic toxic effects both between various mycotoxins (Creppy et al., 2004) and between ochratoxin $\mathrm{A}$ and other known nephrotoxic substances (Weber et al., 2005). However, as the mechanism of action of many mycotoxins, particularly those with nephrotoxic potential remains to be elucidated, the nature of these interactions and their potential importance for risk assessment is still unclear (O'Brien and Dietrich, 2005a).

Apart from binary combinations (Speijers and Speijers, 2004) the in vitro effects of combinations of toxins commonly produced by Aspergillus and Penicillium species has to our knowledge, not yet been investigated. Considering the coincident production of ochratoxins with other mycotoxins, it is very likely, that humans and animals are always exposed to mixtures rather than to individual compounds. Therefore, mixture toxicity data is needed for an improved and more realistic risk assessment.

In the present study, two mycotoxins, (CIT and PAT) often found in combination with ochratoxins (Speijers and Speijers, 2004), were chosen to investigate possible interactive effects with ochratoxins (OTA and OTB) using the porcine renal cell line LLC-PK1, a well-established model for cytotoxicity studies with mycotoxins (Dietrich et al., 2001; Gstraunthaler and Pfaller, 1992). This study was performed in four phases, forming a step-wise approach to test combination toxicity. Phase one consisted of preliminary assays to screen for suitable concentrations of the individual toxins for subsequent mixture testing. In the second phase, a full factorial design was applied to test binary combinations of both ochratoxins. Tested and predicted concentration-response curves were compared to evaluate potential synergistic modes of action. In the third phase, a central composite design was used to screen for possible interactions of all four mycotoxins (Feron et al., 1998; Groten et al., 1998; Tajima et al., 2002). Toxins indicated to interact with each other in phase three were further tested in a full factorial assay design (phase four) to confirm their interactive effects.

The aim of the study was to characterize the individual and combined effects of the four selected toxins and to identify possible interactive effects between them, thus providing additional data for comparison with other in vitro and in vivo studies possibly leading to an improved understanding of dietary relevant exposure and risk scenarios.

\section{Materials and methods}

\subsection{Mycotoxins and reagents}

Highly purified ochratoxin A and B ( $>98 \%$ purity, benzene free) were kindly provided by Dr. M.E. Stack, US FDA, Washington, DC. Media, FBS and other cell culture reagents were purchased from PAA Laboratories $\mathrm{GmbH}$, Cölbe, Germany. Unless otherwise stated, all other chemicals were purchased from Sigma-Aldrich $\mathrm{GmbH}$, Seelze, Germany, and were of the highest quality commercially available.

Sterile stock solutions of each mycotoxin were prepared in $0.1 \mathrm{M} \mathrm{NaHCO}$, deionized water and absolute ethanol for OTA and OTB (each $4 \mathrm{mM})$, PAT (4 mM) and CIT (18 mM), respectively. Stock solutions were diluted in the corresponding vehicle and pipetted directly into the cell culture medium with a dilution factor of 40. The vehicle concentrations employed have been previously shown not to have significant effects on the endpoint tested.

\subsection{Cell cultures and treatments}

LLC-PK 1 cells were obtained from the European Collection of Cell Cultures, Salisbury, UK (ECACC No. 86121112) and were cultured in DMEM supplemented with $10 \%$ FBS and antibiotics (with a final concentration of $100,000 \mathrm{U} / 1$ penicillin and $100 \mathrm{mg} / 1$ streptomycin) under standard conditions and subcultured in the ratio 1:10 twice per week. Passages 1-20 were used for experiments. Cells were seeded at a density of $1 \times 10^{4}$ cells/ $\mathrm{cm}^{2}$ in 24-well tissue culture plates (Greiner Bio-One $\mathrm{GmbH}$, Frickenhausen, Germany) and incubations with the various toxins were started $24 \mathrm{~h}$ after seeding and continued for 24, 48, 72 or $96 \mathrm{~h}$. As described previously (Dietrich et al., 2001), cells maintained under serum-free conditions appeared significantly more susceptible to smallest disturbances, be these of a chemical or physical nature, resulting in detachment from the substrate, 
thus all experiments were carried out in serum-replete medium.

\subsection{Cytotoxicity endpoint: MTT reduction assay}

MTT reduction was assayed spectrophotometrically using a microtiter plate reader (Tecan $\mathrm{GmbH}$, Crailsheim, Germany) as previously described in detail (Dietrich et al., 2001). Briefly, following the exposure period, the cells were incubated with $250 \mu \mathrm{g} \mathrm{MTT} / \mathrm{ml}$ medium at $37^{\circ} \mathrm{C}$ for $1.5 \mathrm{~h}$. The supernatants were then discarded and the intracellular dye was solubilized with $95 \%(\mathrm{v} / \mathrm{v})$ isopropanol $/ 5 \%(\mathrm{v} / \mathrm{v})$ formic acid. Absorbances were read at $550 \mathrm{~nm}$.

\subsection{Preliminary concentration-response experiments}

In order to determine suitable testing concentrations for interaction experiments, individual concentrationresponse curves were established for each mycotoxin using at least seven concentrations in the $\mathrm{nM}$ to $\mu \mathrm{M}$ range. From these data no effect limits and 30\% effect limits were estimated and used as indicators for the choice of range limits for subsequent mixture testing (the combined effect should not reach $100 \%$ effect compared to control). Five equidistant concentrations in that range were calculated for further use, where the lowest concentration was not lower than the no effect limit and the highest concentration did not exceed 30\% effect limit (see natural values in Table 1).

\subsection{Full factorial assay for binary mixtures with ochratoxins}

Each toxin was tested individually to obtain concentration-response curves for the respective five equidistant concentrations. Thereafter, in a full factorial assay, all combinations of OTA or OTB with PAT and CIT were tested in both exposure sequences as indicated in the results section. As all toxins were added individually to the cell cultures, a certain time interval between the addition of the first and the second toxin, which potentially could influence the response observed, was inevitable. This time interval, however, never exceeded $5 \mathrm{~min}$.

Table 1

Nominal concentration range for mixture testing

\begin{tabular}{llllr}
\hline $\begin{array}{l}\text { Coded concentration } \\
\text { values }\end{array}$ & $\begin{array}{l}\text { OTA } \\
(\mu \mathrm{M})\end{array}$ & $\begin{array}{l}\text { OTB } \\
(\mu \mathrm{M})\end{array}$ & $\begin{array}{l}\text { PAT } \\
(\mu \mathrm{M})\end{array}$ & $\begin{array}{r}\text { CIT } \\
(\mu \mathrm{M})\end{array}$ \\
\hline-2 & 10.0 & 25.00 & 0.1000 & 70.0 \\
-1 & 11.0 & 31.25 & 0.3875 & 95.0 \\
0 & 12.0 & 37.50 & 0.6750 & 120.0 \\
+1 & 13.0 & 43.75 & 0.9625 & 145.0 \\
+2 & 14.0 & 50.00 & 1.2500 & 170.0 \\
\hline
\end{tabular}

\subsection{Inscribed central composite design for complete} mixtures

An inscribed central composite design including a fractional factorial part was applied with four factors, namely OTA $\left(X_{1}\right)$, OTB $\left(X_{2}\right)$, PAT $\left(X_{3}\right)$ and CIT $\left(X_{4}\right)$ in order to maximally reduce the number of possible toxin combinations from $5^{4}$ (all possible combinations of every concentration of each toxin) to 17 . The coded and natural values of the factors are shown in Table 1 . The selected response parameter was MTT reduction after $48 \mathrm{~h}$ exposure. The design matrix is shown in Table 3 . The minimal number $(n)$ of runs (toxin combinations) was based on the number of design factors $(k=4$ mycotoxins) as follows: $n=2^{k} / 2$ cube points $+2 k$ star points +1 center point $=2^{4} / 2+2 * 4+1=8+8+$ $1=17$ runs (the design matrix is shown in Table 3 ). All 17 runs were repeated independently at least three times in duplicate. The sequence of toxin addition was always OTA, OTB, PAT, CIT and the time interval between addition of the first and last toxin never exceeded $5 \mathrm{~min}$. To investigate time-dependence, exposures of 24 $\left(Y_{1}\right), 72\left(Y_{3}\right)$ and $96\left(Y_{4}\right) \mathrm{h}$ were compared to the data obtained following $48 \mathrm{~h}$ exposure $\left(Y_{2}\right)$. The behavior of the system was described by the following quadratic model equation with 15 terms, which includes all terms regardless of their significance:

$$
\begin{aligned}
Y_{n}= & b_{0}+b_{1} X_{1}+b_{2} X_{2}+b_{3} X_{3}+b_{4} X_{4}+b_{5} X_{1}^{2}+b_{6} X_{2}^{2} \\
& +b_{7} X_{3}^{2}+b_{8} X_{4}^{2}+b_{9} X_{1} X_{2}+b_{10} X_{1} X_{3}+b_{11} X_{1} X_{4} \\
& +b_{12} X_{2} X_{3}+b_{13} X_{2} X_{4}+b_{14} X_{3} X_{4} .
\end{aligned}
$$

$Y_{n}$ represents the responses, $X_{n}$ the independent variables (here the four toxins), $b_{0}$ the coefficient constant for the offset term and $b_{n}$ the coefficients constants for linear, interaction and quadratic effects.

In order to verify the results from the model, a full factorial design was applied for the interactive components. Therefore, the concentrations of the interactive toxins were varied, whereas the concentrations of the other toxins remained constant using the center (code $0)$ concentrations.

\subsection{Calculations and statistical data analysis}

Absorbance values from cytotoxicity experiments were expressed as percentage of vehicle control for each multiwell plate. Data from the preliminary experiments were analyzed using a two-tailed Dunnett's test. No effect and 30\% effect limits were estimated from concentration-response curves fitted by non-linear regression for sigmoidal concentration-response with variable slope using GraphPad Prism 3.00.

Data was recalculated as percentage effect for comparison and further analysis. Predicted (simple additive) 
effects of combinations of each toxin concentration were calculated using the following equation:

predicted effect $\mathrm{AB}=$ tested effect $\mathrm{A}+$ tested effect $\mathrm{B}$

$$
\pm 0.5(\mathrm{SD} A+\mathrm{SD} \mathrm{B})
$$

Tested and predicted effect curves of the full factorial experiments were compared using an unpaired twotailed $t$-test using GraphPad Prism software. Significant differences are indicated as follows: $p<0.0001\left(^{* * * *}\right)$, $p<0.001\left(^{* * *}\right), p<0.01\left(^{* *}\right), p<0.05\left(^{*}\right)$ and $p \geqslant 0.05$ (not significant). This resulted in data tables with five data sets for each combination and sequence. For the complete design a total of 10 tables were calculated. In order to reduce the amount of data and to increase comprehensibility, each table was further summarized, resulting in one mean value for each combination tested (Fig. 2). These data were summarized for all possible combinations (full factorial test) in Table 2.

Central composite design data were expressed as percentage effect compared to vehicle control and were analyzed by multiple linear regression methodology (Orth and Wenzel, 2003; Steppan et al., 1998) using Essential Regression version 2.219 software (www.geocities.com/ SiliconValley/Network/1032/) as Add-In in MS Excel 2000. The significance of factors was tested using a $t$-test after ANOVA for each exposure time $(p<0.1)$. The resulting mathematical equations were tested for model adequacy by comparing $R^{2}$, Durbin-Watson, $F$ significance, and $R^{2}$ for prediction values. $R^{2}$ indicates the variability of the parameter (response) that is explained by the model. The Durbin-Watson statistic tests the residuals to determine, if there is any significant correlation

Table 2

Results of combinations with ochratoxins

\begin{tabular}{llccc}
\hline Combinations & $\begin{array}{l}\text { Difference between } \\
\text { means }^{\mathrm{a}}\end{array}$ & $\mathrm{SD}$ & $\begin{array}{l}p \text {-Value } \\
\text { summary }\end{array}$ & $R^{2}$ \\
\hline OTB + CIT & -55.7 & 3.4 & $<0.0001$ & 0.97 \\
CIT + OTB & -49.9 & 3.4 & $<0.0001$ & 0.96 \\
OTA + CIT & -45.2 & 3.4 & $<0.0001$ & 0.95 \\
CIT + OTA & -47.6 & 1.8 & $<0.0001$ & 0.99 \\
PAT + OTB & -41.9 & 4.2 & $<0.0001$ & 0.92 \\
OTB + PAT & -42.5 & 6.6 & $<0.001$ & 0.83 \\
OTB + OTA & -20.9 & 2.3 & $<0.001$ & 0.88 \\
OTA + OTB & -22.8 & 4.5 & $<0.01$ & 0.76 \\
PAT + OTA & -11.8 & 1.6 & $<0.01$ & 0.76 \\
OTA + PAT & -8.7 & 7.5 & $\geqslant 0.05$ & 0.15 \\
\hline COT
\end{tabular}

Comparison of predicted vs. tested effects after $48 \mathrm{~h}$ of exposure. Values represent the difference of the individual mean values obtained from a full factorial design.

${ }^{\text {a }}$ Difference between means when predicted and tested concentration curves were compared by a $t$-test. Example for the interpretation of the data: the combination OTB + CIT resulted in a $55.7 \%$ lower predicted than tested cytotoxic effect.

${ }^{\mathrm{b}}$ Values represent means of the concentration-response curve without the data of OTB at the -2 level, which were not significant with $p>0.05$. based on the order in which they occur. The $F$ significance value is a term for model significance. A value of $\leqslant 0.05$ indicates a significant model at the $95 \%$ significance level. $R^{2}$ for prediction indicates the variability of the predicted parameter (predicted response) that is explained by the model.

\section{Results}

\subsection{Preliminary experiments}

Concentration-response curves were established from the data obtained in LLC-PK1 cells and are shown in Fig. 1. Based on the estimated no effect and 30\% effect limits, an appropriate range with five equidistant concentrations was chosen for each toxin for subsequent testing. These are detailed in Table 1.

\subsection{Full factorial assay for binary mixtures with ochratoxins}

The results of the full factorial assays for binary mixtures with OTA and OTB are shown in Table 2. The sequence of toxin addition to the cell cultures did not have any significant effect or only a slight effect (in the OTA-PAT combination experiments, which may be due to poor correlation) on the results. Therefore, all subsequent testing was carried out with the following sequence of toxin addition: OTA, OTB, PAT and CIT.

The results clearly demonstrate, that the tested toxicity was always higher than the predicted (simple additive) toxicity of the binary mixture. Potency orders for combinations with ochratoxins could be established: $\mathrm{CIT}+\mathrm{OTA}>\mathrm{OTB}+\mathrm{OTA}>\mathrm{PAT}+\mathrm{OTA}$ and CIT + $\mathrm{OTB}>\mathrm{PAT}+\mathrm{OTB}>\mathrm{OTA}+\mathrm{OTB}$, with CIT being the most potently interactive compound. As the mechanism(s) of action of the individual toxins have as yet not been elucidated, the reasons for these interactions remain unclear (see Section 4).

\subsection{Inscribed central composite design for complete mixtures}

The results obtained after running the 17 runs of the statistical design and the design matrix are shown in Table 3. Table 4 shows an overview of the estimated values of the factor coefficients and their interactions, together with their $p$-values. The effects with $p$-values higher than 0.1 are insignificant at the $90 \%$ confidence level and were discarded. Further removal of factors with $p$-values higher than 0.05 (95\% confidence level) did not improve model adequacy.

The results of the analysis are summarized in the following equations: 

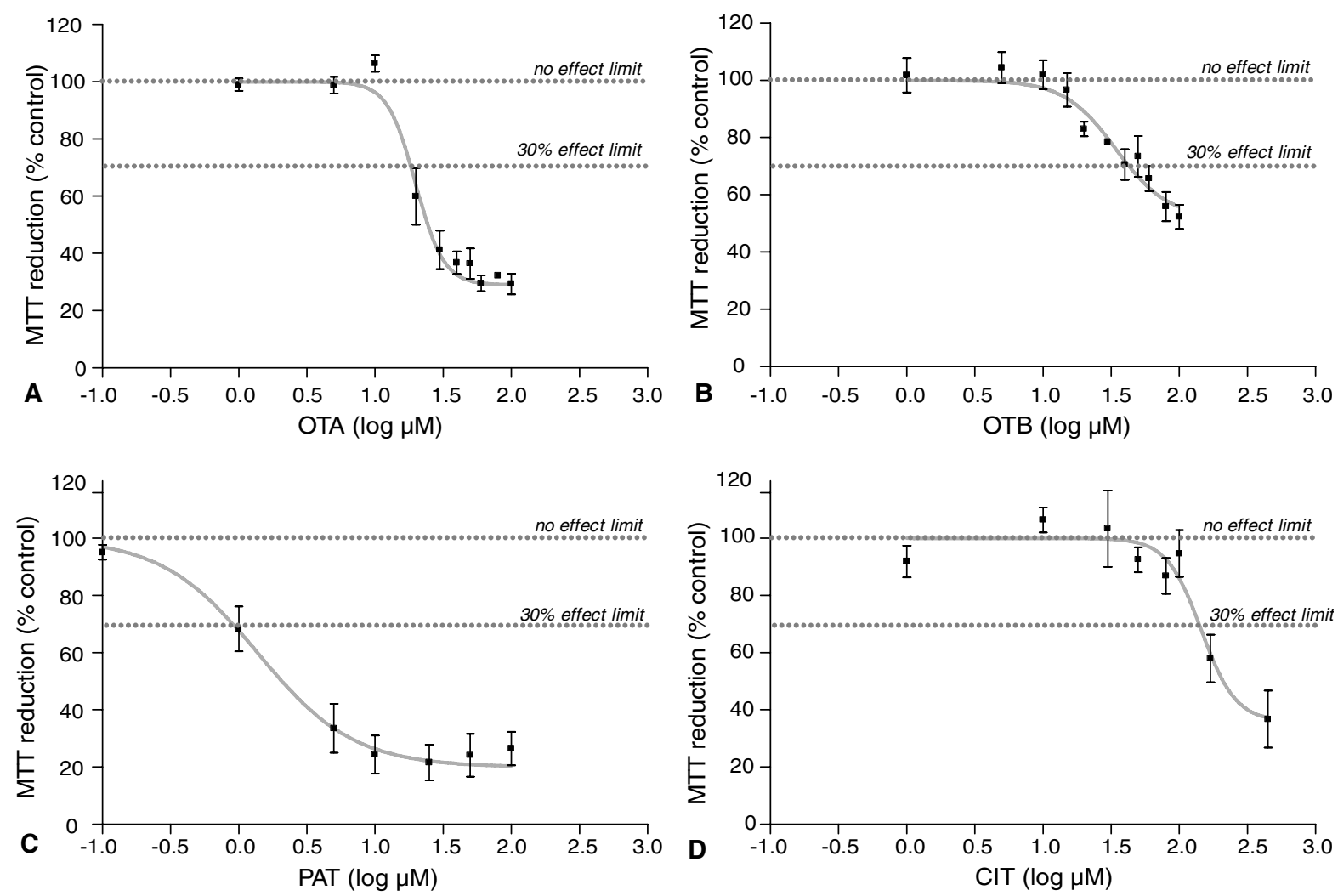

Fig. 1. Concentration-response curves for individual toxins. Concentration-response curves were fitted by non-linear regression as described in Section 2. Data represent arithmetic means \pm SD following $48 \mathrm{~h}$ exposure ( $n \geqslant 3$ independent experiments carried out in duplicate).

$Y_{1}=34.1+5.8 \mathrm{OTA} \times \mathrm{CIT}+4.1 \mathrm{PAT}+3.7 \mathrm{CIT}$

$Y_{2}=54.5+2.9 \mathrm{OTA} \times \mathrm{CIT}+2.0 \mathrm{PAT}+2.1 \mathrm{CIT}$

$$
+1.8 \mathrm{OTB}+1.4 \mathrm{CIT}^{2}
$$

$Y_{3}=70.2+2.3 \mathrm{OTA} \times \mathrm{CIT}-1.6 \mathrm{PAT}^{2}$

$Y_{4}=67.3+2.5 \mathrm{OTA} \times \mathrm{CIT}+1.4 \mathrm{OTB}+1.7 \mathrm{CIT}^{2}$

where $Y_{1}, Y_{2}, Y_{3}$ and $Y_{4}$ represent the $24,48,72$ and $96 \mathrm{~h}$ endpoints, respectively. OTA and CIT were observed to display interactive toxicity at all time points tested. This interaction was further characterized using a full factorial assay (see Section 3.4). In contrast to the binary combinations, the interaction of OTB and CIT, did not appear to be as strong when these toxins were used in a quaternary combination. It is possible that the effect is weakened or masked by the effects of the other toxins.

Table 5 shows the results of model adequacy testing. The investigated parameters $\left(R^{2}\right.$, Durbin-Watson value, $F$ significance value and $R^{2}$ for prediction) indicated a good-to-medium coverage of the experimental data by the model, e.g., the variability of the $48 \mathrm{~h}$ model is covered by more than $70 \%$, however, the predictive performance of the models seemed to be unsatisfactory.

\subsection{Full factorial assay for model validation}

The results of the full factorial assays for model validation are shown in Fig. 3A-D. Here, the predicted values by the model equations were tested by varying the concentrations of the interactive compounds while keeping the concentrations of the other two toxins constant at the center level. The results are $80 \%$ in accordance with the predicted results, which is a better prediction success than assumed from the model adequacy testing results.

\section{Discussion}

In order to provide a reliable basis for the investigation of the cytotoxic effects of mycotoxin combinations, it was first necessary to assess the effects of the individual substances using a standardized system.

The cytotoxicity of ochratoxin A has been investigated by several authors and the $\mathrm{EC}_{50}$ values were generally observed to lie within the micromolar range. Differences in the specific $\mathrm{EC}_{50} \mathrm{~s}$ reported can probably be attributed to the use of different cell lines, different endpoints (e.g., MTT reduction, neutral red uptake, cell counting or LDH release) or indeed to the presence or absence of serum in the culture medium (Bondy and Armstrong, 1998; Dietrich et al., 2001). Interestingly, primary cells have been demonstrated to be more susceptible to the cytotoxic effects of both OTA and OTB when crystal violet staining of intact nuclei is taken as 
(1) Effects of individual toxins were tested.

(2) Theoretical additive effects of binary mixtures were calculated $\rightarrow$ predicted effect $(\%)$

(3) Effects of binary mixtures were measured $\rightarrow$ tested effect $(\%)$

Example: lowest concentration of CIT + all five concentrations of OTA:

\begin{tabular}{lccccr}
\hline $\begin{array}{l}\text { CIT } \\
{[\boldsymbol{\mu M}]}\end{array}$ & $\begin{array}{c}\text { OTA } \\
{[\boldsymbol{\mu M}]}\end{array}$ & $\begin{array}{c}\text { predicted effect } \\
{[\%]}\end{array}$ & $\begin{array}{c}\text { SD } \\
{[\%]}\end{array}$ & $\begin{array}{c}\text { tested effect } \\
{[\%]}\end{array}$ & $\begin{array}{r}\text { SD } \\
{[\%]}\end{array}$ \\
\hline 70.0 & 10.0 & 8.0 & 8.0 & 41.8 & 4.9 \\
70.0 & 11.0 & 12.3 & 10.0 & 44.7 & 16.9 \\
70.0 & 12.0 & 6.2 & 14.0 & 43.8 & 17.7 \\
70.0 & 13.0 & 10.9 & 12.0 & 49.6 & 10.3 \\
70.0 & 14.0 & 14.7 & 11.0 & 48.0 & 11.4 \\
\hline
\end{tabular}

(4) Predicted and tested effect curves were compared by a t-test Example: lowest concentration of CIT + all five concentrations of OTA:

\begin{tabular}{lcccc}
\hline Sample & $\begin{array}{c}\text { Significance } \\
\text { level }\end{array}$ & $\begin{array}{c}\text { Difference between } \\
\text { means [\%] }\end{array}$ & $\begin{array}{c}\text { SD } \\
{[\%]}\end{array}$ & $\mathbf{R}^{2}$ \\
\hline CIT $[70 \mu \mathrm{M}]+$ & $* * *$ & -35.2 & 2.1 & 0.97 \\
OTA $[10-14 \mu \mathrm{M}]$ & & & & \\
\hline
\end{tabular}

(5) t-test results were summarized for all possible combinations (full factorial test) Example: all five concentrations of CIT + all five concentrations of OTA:

\begin{tabular}{|c|c|c|c|c|}
\hline Sample & $\begin{array}{c}\text { Significance } \\
\text { level }\end{array}$ & $\begin{array}{c}\text { Difference between } \\
\text { means [\%] }\end{array}$ & $\begin{array}{c}\text { SD } \\
{[\%]}\end{array}$ & $\mathbf{R}^{2}$ \\
\hline $\begin{array}{l}\text { CIT }[70 \mu \mathrm{M}]+ \\
\text { OTA }[10-14 \mu \mathrm{M}]\end{array}$ & $* * *$ & -35.2 & 2.1 & 0.97 \\
\hline $\begin{array}{l}\text { CIT }[95 \mu \mathrm{M}]+ \\
\text { OTA }[10-14 \mu \mathrm{M}]\end{array}$ & $* * *$ & $-43,3$ & 1,8 & 0,99 \\
\hline $\begin{array}{l}\text { CIT }[120 \mu \mathrm{M}]+ \\
\text { OTA }[10-14 \mu \mathrm{M}]\end{array}$ & $* * *$ & $-52,6$ & 1,7 & 0,99 \\
\hline $\begin{array}{l}\text { CIT }[145 \mu \mathrm{M}]+ \\
\text { OTA }[10-14 \mu \mathrm{M}]\end{array}$ & $* * *$ & $-58,6$ & 1,7 & 0,99 \\
\hline $\begin{array}{l}\text { CIT }[170 \mu \mathrm{M}]+ \\
\text { OTA }[10-14 \mu \mathrm{M}]\end{array}$ & $* * *$ & $-48,4$ & 1,8 & 0,99 \\
\hline Means & $* * *$ & -47.6 & 1.8 & 0.99 \\
\hline
\end{tabular}

Fig. 2. Calculation of results from the binary mixture testing experiments. Calculational basis for the results shown in Table 2.

endpoint (O'Brien et al., 2001), whereas this was not apparent via assessment of other endpoints (Dietrich et al., 2001). OTB has often been reported to be less toxic than OTA in vivo (Doster et al., 1972, 1974; Størmer et al., 1985) and in vitro. However, more recent in vitro data brings this into question (Mally et al., 2005). Preliminary citrinin cytotoxicity assays (data not shown) in our laboratory using porcine kidney cells (PKC) are largely in agreement with those of other authors (Bondy and Armstrong, 1998) yielding $\mathrm{EC}_{50}$ values of $>400 \mu \mathrm{M}$. Other authors have reported far lower $\mathrm{EC}_{50}$ values (approximately factor 10) in MDBK and PFBK cells (Yoneyama et al., 1986). Similarly, the detection of patulin-mediated cytotoxic effects appears to be dependent on the choice of cell system and detection method employed, with cytotoxic concentrations ranging between 0.1 and $>10 \mu \mathrm{M}$ (Burghardt et al., 1992; Riley et al., 1990). In agreement with these authors, preliminary assays (data not shown) in our laboratory showed that $\mathrm{EC}_{30}$ in $\mathrm{PKC}$ to be approximately $1-5 \mu \mathrm{M}$ after $48 \mathrm{~h}$ of exposure using MTT reduction as endpoint.

A toxicity ranking for single toxin experiments of PAT $>$ OTA $\geqslant$ OTB $>$ CIT, with CIT being at least 10 times less acutely toxic than PAT, could be drawn from literature in vitro data, which is consistent with the results presented here. A further comparison with in vivo data showed the same toxicity ranking.

In the current study, the presented results of the comparison of predicted (simple additive) and tested mixture effects in binary mixtures always resulted in higher toxicity of CIT and PAT when combined with OTA or 
Table 3

Design matrix and results of the inscribed central composite design

\begin{tabular}{|c|c|c|c|c|c|c|c|c|c|}
\hline Run no. & Points & $X_{1}$ & $X_{2}$ & $X_{3}$ & $X_{4}$ & $Y_{1}$ & $Y_{2}$ & $Y_{3}$ & $Y_{4}$ \\
\hline 1 & Cube & -1 & -1 & -1 & -1 & 36.2 & 52.6 & 72.1 & 67.3 \\
\hline 2 & & -1 & -1 & +1 & +1 & 43.4 & 58.9 & 69.4 & 67.0 \\
\hline 3 & & -1 & +1 & -1 & +1 & 27.1 & 54.2 & 61.9 & 64.4 \\
\hline 4 & & -1 & +1 & +1 & -1 & 39.8 & 61.0 & 69.8 & 69.9 \\
\hline 5 & & +1 & -1 & -1 & +1 & 35.8 & 59.3 & 73.2 & 72.6 \\
\hline 6 & & +1 & -1 & +1 & -1 & 30.7 & 53.9 & 69.8 & 66.6 \\
\hline 7 & & +1 & +1 & -1 & -1 & 14.7 & 47.1 & 67.1 & 65.8 \\
\hline 8 & & +1 & +1 & +1 & +1 & 50.5 & 64.2 & 71.1 & 74.0 \\
\hline 9 & Star & -2 & 0 & 0 & 0 & 33.7 & 55.6 & 68.3 & 70.0 \\
\hline 10 & & +2 & 0 & 0 & 0 & 27.9 & 53.5 & 69.5 & 67.8 \\
\hline 11 & & 0 & -2 & 0 & 0 & 24.7 & 46.6 & 67.0 & 61.2 \\
\hline 12 & & 0 & +2 & 0 & 0 & 36.6 & 60.3 & 69.6 & 72.3 \\
\hline 13 & & 0 & 0 & -2 & 0 & 28.2 & 49.8 & 65.0 & 67.1 \\
\hline 14 & & 0 & 0 & +2 & 0 & 35.9 & 53.2 & 61.0 & 63.3 \\
\hline 15 & & 0 & 0 & 0 & -2 & 31.6 & 56.3 & 67.5 & 75.0 \\
\hline 16 & & 0 & 0 & 0 & +2 & 43.8 & 62.5 & 76.9 & 74.3 \\
\hline 17 & Center & 0 & 0 & 0 & 0 & 38.3 & 59.2 & 68.5 & 72.4 \\
\hline
\end{tabular}

The factors $X_{1}$ (OTA), $X_{2}$ (OTB), $X_{3}$ (PAT) and $X_{4}$ (CIT) are expressed as coded values and the values of the corresponding responses $Y_{1}\left(24 \mathrm{~h}\right.$ ), $Y_{2}$ $(48 \mathrm{~h}), Y_{3}(72 \mathrm{~h})$ and $Y_{4}(96 \mathrm{~h})$ are expressed as percentage effect compared to control of $n \geqslant 3$ independent experiments carried out in duplicate.

Table 4

Test of significance of factors after ANOVA for the models $Y_{1}, Y_{2}, Y_{3}$ and $Y_{4}$

\begin{tabular}{|c|c|c|c|c|c|c|c|c|}
\hline \multirow[t]{2}{*}{ Factor or interaction } & \multicolumn{2}{|c|}{ Parameter $Y_{1}$} & \multicolumn{2}{|c|}{ Parameter $Y_{2}$} & \multicolumn{2}{|c|}{ Parameter $Y_{3}$} & \multicolumn{2}{|c|}{ Parameter $Y_{4}$} \\
\hline & $\begin{array}{l}\text { Coefficient } \\
\text { (est. effect) }\end{array}$ & $p$-value & $\begin{array}{l}\text { Coefficient } \\
\text { (est. effect) }\end{array}$ & $p$-value & $\begin{array}{l}\text { Coefficient } \\
\text { (est. effect) }\end{array}$ & $p$-value & $\begin{array}{l}\text { Coefficient } \\
\text { (est. effect) }\end{array}$ & $p$-value \\
\hline Constant & 34.06 & $9.624 \mathrm{E}-13$ & 54.51 & $1.070 \mathrm{E}-14$ & 70.21 & $1.187 \mathrm{E}-19$ & 67.28 & $1.694 \mathrm{E}-18$ \\
\hline OTA*CIT & 5.820 & 0.00796 & 2.892 & 0.02994 & 2.257 & $0.05446^{\mathrm{a}}$ & 2.495 & 0.03196 \\
\hline PAT & 4.124 & 0.00786 & 1.967 & 0.03542 & n.s. & n.s. & n.s. & n.s. \\
\hline CIT & 3.741 & 0.01377 & 2.137 & 0.02455 & n.s. & n.s. & n.s. & n.s. \\
\hline OTВ & n.s. & n.s. & 1.826 & 0.04794 & n.s. & n.s. & 1.426 & $0.07428^{\mathrm{a}}$ \\
\hline $\mathrm{CIT}^{*} \mathrm{CIT}$ & n.s. & n.s. & 1.352 & $0.06427^{\mathrm{a}}$ & n.s. & n.s. & 1.710 & 0.01226 \\
\hline PAT*PAT & n.s. & n.s. & n.s. & n.s. & -1.633 & 0.01794 & n.s. & n.s. \\
\hline
\end{tabular}

est. effect, estimated effect; n.s., not significant with $p>0.1 ; Y_{n}$, response parameters with $Y_{1}(24 \mathrm{~h}), Y_{2}(48 \mathrm{~h}), Y_{3}(72 \mathrm{~h}), Y_{4}(96 \mathrm{~h})$.

${ }^{a}$ Values are not significant at the $95 \%$ confidence level $(p>0.05)$, but significant at the $90 \%$ confidence level $(p<0.1)$. Removal of these factors did not improve model adequacy (see Table 5).

Table 5

Test of model adequacy

\begin{tabular}{|c|c|c|c|c|}
\hline Model $^{\mathrm{a}}$ & $R^{2 \mathrm{~b}}$ & Durbin-Watson statistic ${ }^{c}$ & $F$ significance $^{\mathrm{d}}$ & $R^{2}$ for prediction \\
\hline$Y_{1}$ & 0.681 & 1.861 & 0.00154 & 0.462 \\
\hline$Y_{2}$ & 0.717 & 2.181 & 0.00840 & 0.322 \\
\hline$Y_{3}$ & 0.453 & 2.245 & 0.01468 & 0.200 \\
\hline$Y_{4}$ & 0.580 & 2.004 & 0.00856 & 0.326 \\
\hline
\end{tabular}

${ }^{a} Y_{n}$, response parameters with $Y_{1}(24 \mathrm{~h}), Y_{2}(48 \mathrm{~h}), Y_{3}(72 \mathrm{~h}), Y_{4}(96 \mathrm{~h})$.

${ }^{\mathrm{b}} R^{2}$ indicates the variability of the parameter (response) that is explained by the model.

c The Durbin-Watson statistic tests the residuals to determine, if there is any significant correlation based on the order in which they occur. If the Durbin-Watson value is greater than 1.77 (according to Durbin-Watson table at $\alpha=0.025$ ) there is probably no autocorrelation in the residuals.

${ }^{d}$ The $F$ significance value is a term for model significance. A value of $\leqslant 0.05$ indicates a significant model at the $95 \%$ significance level.

e $R^{2}$ for prediction indicates the variability of the predicted parameter (predicted response) that is explained by the model.

OTB in LLC-PK1 cells. For comparison, the human renal cell line IHKE showed these elevated effects only in combinations including CIT and the effects were not as pronounced (at least a factor 2 lower) as in LLC-PK1 

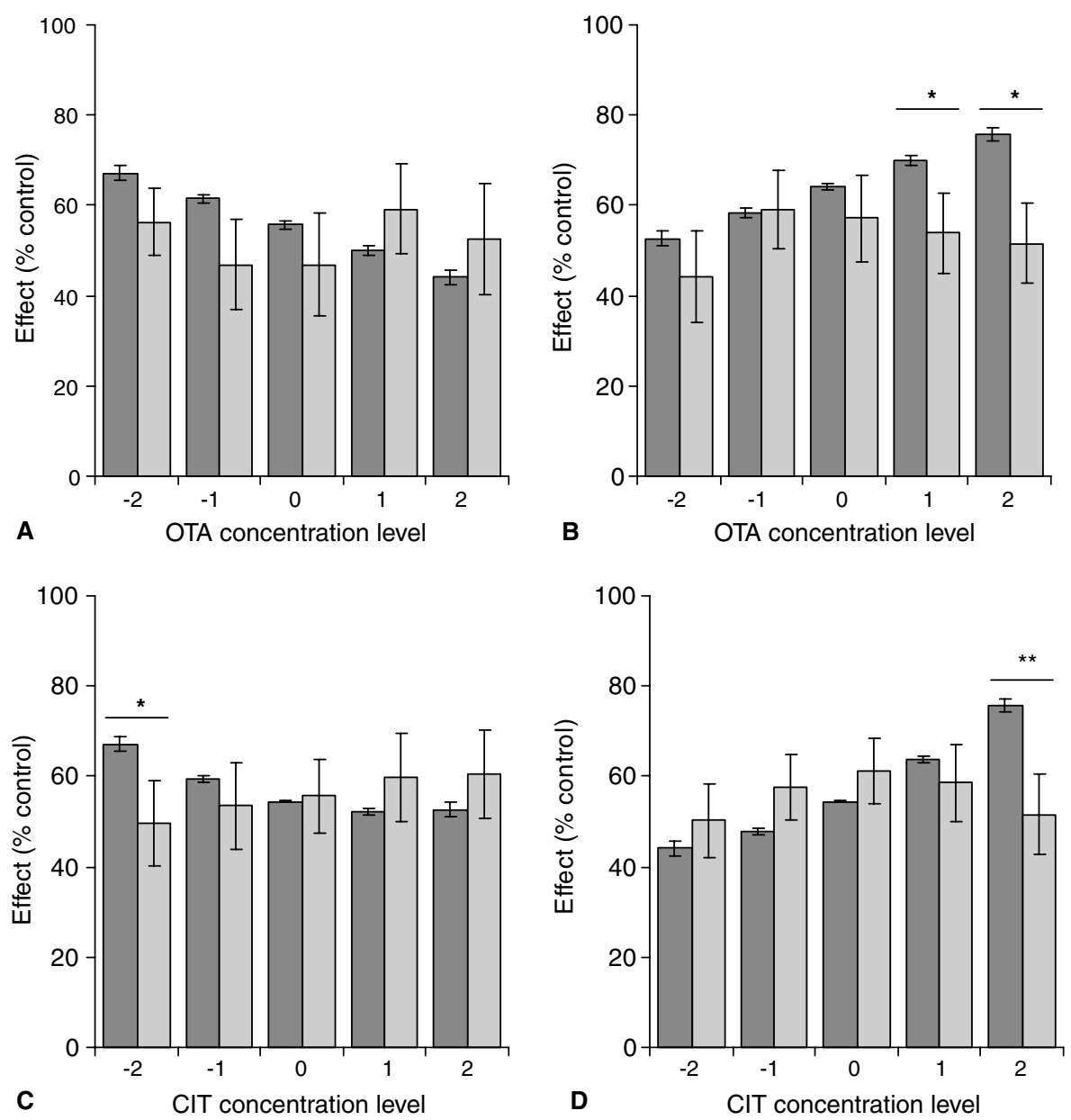

Fig. 3. Comparison of predicted and tested effects of the $48 \mathrm{~h}$ model $\left(Y_{2}\right)$. Results of the full factorial design for the interactive components. The concentrations of the first interactive toxin were varied as indicated on the $x$-axis, the second interactive toxin was varied as follows: (A) CIT ( -2 ), (B) CIT $(+2),($ C) OTA $(-2),(D)$ OTA $(+2)$, whereas the concentrations of the other two toxins were kept constant using the center (code 0) concentrations. Values of predicted (dark grey) and tested (light grey) effects are expressed as percentage effect \pm SD compared to vehicle control of $n=3$ independent experiments carried out in quadruplicate. Values differ significantly with $p<0.05\left({ }^{*}\right)$ or $p<0.01\left({ }^{* *}\right)$ using an unpaired two-tailed $t$-test.

cells (Heussner et al., 2004). Hence, our results support the hypothesis of a superadditive or synergistic mode of action of these mycotoxins in renal cells.

The results of the central composite design assays with all four toxins showed clearly that there is at least one synergistic interaction between the binary pairs of the mycotoxins in the mixture, namely CIT and OTA. This interaction was corroborated by the full factorial design data in the last phase of the study.

Literature data is conflicting concerning interactive effects in in vitro and in vivo experimental systems. However, in renal systems, synergistic or additive effects, with particular relevance for ochratoxin/citrinin combinations predominate. A good overview and comparison of combination effects in various systems is given by Speijers and Speijers (2004). Supported by the toxicity data of the individual toxins, it is likely, that not only the individual toxins show large differences depending on species, sex, in vivo or in vitro exposure system, but also the differences in combination toxicity are probably influenced by the same factors.

Central composite design assays are regularly used in other fields of research for example in the development of improved culture or assay conditions (optimization of medium components, etc.) (Cornell, 1990; Moran et al., 2000). When compared to these other applications, the mixture data generated here did not show best achievable adequacy. This is probably due to the relative complexity and inherent variability of cellular responses to toxic insult. Nevertheless, the data are corroborated by subsequent test results and the observations on mycotoxin toxicity in renal cells in general made by ourselves and many other investigators over the last number of years.

The models presented here reflect the observation, that after $24 \mathrm{~h}$ of exposure even to individual toxins, no definitive conclusions can be drawn because of high variability of the cellular responses. This fact may be 
due to handling differences in cell seeding, medium changes etc. between independent assays, which may play a greater role after short-term exposures than after longer exposure times when using unsynchronized cells under serum-replete conditions. The most reliable data is usually obtained after $48 \mathrm{~h}$ with regard to deviations within one experiment and comparisons of independent experiments when single toxins were examined. After 72 or $96 \mathrm{~h}$ an overall severe toxicity is observed, at least in part caused by dead or dying cells triggering further damage to yet viable cells.

In conclusion, this experimental design is suitable for screening purposes, but full factorial assays are necessary to test the specific effects of potential interactive compounds as has also been shown by other authors (Groten et al., 1998; Tajima et al., 2002). These findings should be validated with other cell lines or preferably with primary cells. Both strategies are currently under investigation in our laboratory. While an in vivo risk assessment cannot be directly extrapolated from in vitro data, the results obtained in this study confirm a potential for interactive (synergistic) effects of CIT and OTA and possibly other mycotoxins in cells of renal origin. Therefore, the toxicity of mycotoxin mixtures cannot be accurately predicted only on the basis of the effect of the individual toxins. These aspects must be considered in future risk assessment studies.

\section{Acknowledgements}

We would like to thank M.E. Stack, US FDA, Washington, DC, for providing highly purified ochratoxin A and B and M.A. Biester, J. Hähnlein and R. Tkaschuk for their assistance with the cytotoxicity experiments.

\section{References}

Bondy, G.S., Armstrong, C.L., 1998. Cytotoxicity of nephrotoxic fungal toxins to kidney-derived LLC-PK1 and OK cell lines. Cell Biology and Toxicology 14, 323-332.

Burghardt, R.C., Barhoumi, R., Lewis, E.H., Bailey, R.H., Pyle, K.A., Clement, B.A., Phillips, T.D., 1992. Patulin-induced cellular toxicity: a vital fluorescence study. Toxicology and Applied Pharmacology 112, 235-244.

Cornell, J., 1990. How to Run Mixture Experiments for Product Quality. The ASQC Basic Reference in Quality Control: Statistical Techniques. Quality Press, Milwaukee.

Creppy, E.E., Chiarappa, P., Baudrimaunt, I., Borracci, P., Moukha, S., Carraù, M.R., 2004. Synergistic effects of fumonisin B1 and ochratoxin A: are in vitro cytotoxicity data predictive of in vivo acute toxicity? Toxicology 201, 115-123.

Dietrich, D.R., O'Brien, E., Stack, M.E., Heussner, A.H., 2001. Species- and sex-specific renal cytotoxicity of ochratoxin A and B in vitro. Experimental and Toxicologic Pathology 53, 215-225.

Doster, R.C., Sinnhuber, R.O., Wales, J.H., 1972. Acute intraperitoneal toxicity of ochratoxin $\mathrm{A}$ and $\mathrm{B}$ in rainbow trout (Salmo gairdneri). Food and Cosmetics Toxicology 10, 85-92.
Doster, R.C., Sinnhuber, R.O., Pawlowski, N.E., 1974. Acute intraperitoneal toxicity of ochratoxin A and B derivatives in rainbow trout (Salmo gairdneri). Food and Cosmetics Toxicology 12, 499505.

Engelhardt, G., 2004. Mykotoxine-Giftige Stoffwechselprodukte von Schimmelpilzen (Mycotoxins-Poisonous metabolites of moulds), $<$ http://www.vis-ernaehrung.bayern.de/ $>$.

Feron, V.J., Cassee, F.R., Groten, J.P., 1998. Toxicology of chemical mixtures: international perspective. Environmental Health Perspectives $106,1281-1289$.

Fillastre, J.P., 1997. Ochratoxin-induced animal and human nephrotoxicity. Bulletin de l'Acedemie Nationale de Medecine 181, 14471463.

Groten, J.P., Tajima, O., Feron, V.J., Schoen, E.D., 1998. Statistically designed experiments to screen chemical mixtures for possible interactions. Environmental Health Perspectives 106, 13611365 .

Gstraunthaler, G., Pfaller, W., 1992. Continuous cell lines as in vitro tools to study nephrotoxicity. In: Watson, R.R. (Ed.), In Vitro Methods of Toxicology, pp. 93-113.

Heussner, A.H., O’Brien, E., Haehnlein, J., Biester, M.A., Dietrich, D.R., 2004. Comparison of interactive cytotoxic effects of selected mycotoxins on renal cells. Toxicological Sciences 78 (S-1), 89.

Mally, A., Keim-Heusler, H., Amberg, A., Kurz, M., Zepnik, H., Mantle, P., Volkel, W., Hard, G.C., Dekant, W., 2005. Biotransformation and nephrotoxicity of ochratoxin $\mathrm{B}$ in rats. Toxicology and Applied Pharmacology 206, 43-53.

Martins, M.L., Gimeno, A., Martins, H.M., Bernardo, F., 2002. Cooccurrence of patulin and citrinin in Portuguese apples with rotten spots. Food Additives and Contaminants 19, 568-574.

Moran, E.B., McGowan, S.T., McGuire, J.M., Frankland, J.E., Oyebade, I.A., Waller, W., Archer, L.C., Morris, L.O., Pandya, J., Nathan, S.R., Smith, L., Cadette, M.L., Michalowski, J.T., 2000. A systematic approach to the validation of process control parameters for monoclonal antibody production in fed-batch culture of a murine myeloma. Biotechnology and Bioengineering 69, 242-255.

O'Brien, E., Heussner, A.H., Dietrich, D.R., 2001. Species-, sex-, and cell type-specific effects of ochratoxin A and B. Toxicological Sciences 63, 256-264.

O'Brien, E., Dietrich, D.R., 2005a. Mycotoxins affecting the kidney. In: Tarloff, J., Lash, L. (Eds.), Toxicology of the Kidney. Taylor \& Francis, London.

O'Brien, E., Dietrich, D.R., 2005b. Ochratoxin A: the continuing enigma. Critical Reviews in Toxicology 35, 33-60.

Orth, A., Wenzel, D., 2003. Leitfaden-Modellgestützte Versuchsplanung und Optimierung (Guideline-Model-based assay design and optimization), <http://www.fh-frankfurt.de/ orth/Lehrveranstaltungen/Versuchsplanung/DoE-Leitfaden.pdf/>.

Peraica, M., Radic, B., Lucic, A., Pavlovic, M., 1999. Toxic effects of mycotoxins in humans. Bulletin of the World Health Organisation 77, 754-766.

Pfohl-Leszkowicz, A., Petkova-Bocharova, T., Chernozemsky, I.N., Castegnaro, M., 2002. Balkan endemic nephropathy and associated urinary tract tumours: a review on aetiological causes and the potential role of mycotoxins. Food Additives and Contaminants 19, 282-302.

Riley, R.T., Hinton, D.M., Showker, J.L., Rigsby, W., Norred, W.P., 1990. Chronology pf patulin-induced alterations in membrane function of cultured renal cells, LLC-PK1. Toxicology and Applied Pharmacology 102, 128-141.

Speijers, G.J.A., Speijers, M.H.M., 2004. Combined toxic effects of mycotoxins. Toxicology Letters 153, 91-98.

Steppan, D.D., Werner, J., Yeater, R.P., 1998. Essential regression and experimental design for chemists and engineers, <www.geocities.com/SiliconValley/Network/1032/>. 
Stoev, S.D., 1998. The role of ochratoxin A as a possible cause of Balkan Endemic Nephropathy and its risk evaluation. Veterinary and Human Toxicology 40, 352-360.

Stoev, S.D., Hald, B., Mantle, P.G., 1998. Porcine nephropathy in Bulgaria: a progressive syndrome of complex or uncertain (mycotoxin) aetiology. Veterinary Record 142, 190-194.

Stoev, S.D., Paskalev, M., Macdonald, S., Mantle, P.G., 2002. Experimental one year ochratoxin A toxicosis in pigs. Experimental and Toxicologic Pathology 53, 481-487.

Størmer, F.C., Kolsaker, P., Holm, H., Rogstad, S., Elling, F., 1985. Metabolism of ochratoxin B and its possible effects upon the metabolism and toxicity of ochratoxin A in rats. Applied and Environmental Microbiology 49, 1108-1112.

Tajima, O., Schoen, E.D., Feron, V.J., Groten, J.P., 2002. Statistically designed experiments in a tiered approach to screen mixtures of
Fusarium mycotoxins for possible interactions. Food and Chemical Toxicology 40, 685-695.

Tatu, C.A., Orem, W.H., Finkelman, R.B., Feder, G.L., 1998. The etiology of Balkan endemic nephropathy: still more questions than answers. Environmental Health Perspectives 106, 689-700.

Wafa, E.W., Yahya, R.S., Sobh, M.A., Eraky, I., El Baz, H., El Gayar, H.A.M., Betbeder, A.M., Creppy, E.E., 1998. Human ochratoxicosis and nephropathy in Egypt: a preliminary study. Human and Experimental Toxicology 17, 124-129.

Weber, F., Freudinger, R., Schwerdt, G., Gekle, M., 2005. A rapid screening method to test apoptotic synergisms of ochratoxin A with other nephrotoxic substances. Toxicology in Vitro 19, 135-145.

Yoneyama, M., Sharma, R.P., Kleinschuster, S.J., 1986. Cytotoxicity of citrinin in cultured kidney epithelial cell systems. Ecotoxicology and Environmental Safety 11, 100-111. 